\title{
Bronchodilator Action of Inhaled Nitric Oxide in Guinea Pigs
}

\author{
Patrick M. Dupuy, ${ }^{*}$ Stephanie A. Shore," Jeffrey M. Drazen, ${ }^{* 5}$ Claes Frostell, * W. Adam Hill, * and Warren M. Zapol * \\ ${ }^{*}$ Department of Anaesthesia, Harvard Medical School at Massachusetts General Hospital, Boston, Massachusetts 02114; ${ }^{\ddagger}$ Departments \\ of Medicine, Beth Israel and Brigham and Women's Hospital, Harvard Medical School, Boston, Massachusetts 02115; \\ and ${ }^{\S}$ Respiratory Biology Program, Harvard School of Public Health, Boston, Massachusetts 02115
}

\begin{abstract}
The effects of inhaling nitric oxide (NO) on airway mechanics were studied in anesthetized and mechanically ventilated guinea pigs. In animals without induced bronchoconstriction, breathing $300 \mathrm{ppm}$ NO decreased baseline pulmonary resistance $\left(R_{\mathrm{L}}\right)$ from $0.138 \pm 0.004(\operatorname{mean} \pm \mathrm{SE})$ to $0.125 \pm 0.002$ $\mathrm{CmH}_{2} \mathrm{O} / \mathrm{ml} \cdot \mathrm{s}(P<0.05)$. When an intravenous infusion of methacholine $(3.5-12 \mu \mathrm{g} / \mathrm{kg} \cdot \mathrm{min})$ was used to increase $R_{\mathrm{L}}$ from $0.143 \pm 0.008$ to $0.474 \pm 0.041 \mathrm{cmH}_{2} \mathrm{O} / \mathrm{ml} \cdot \mathrm{s}(P<0.05)$, inhalation of 5-300 ppm NO-containing gas mixtures produced a dose-related, rapid, consistent, and reversible reduction of $\boldsymbol{R}_{\mathrm{L}}$ and an increase of dynamic lung compliance. The onset of bronchodilation was rapid, beginning within $30 \mathrm{~s}$ after commencing inhalation. An inhaled NO concentration of $15.0 \pm 2.1 \mathrm{ppm}$ was required to reduce $\boldsymbol{R}_{\mathrm{L}}$ by $50 \%$ of the induced bronchoconstriction. Inhalation of $100 \mathrm{ppm}$ NO for $1 \mathrm{~h}$ did not produce tolerance to its bronchodilator effect nor did it induce substantial methemoglobinemia $(<2 \%)$. The bronchodilating effects of NO were additive with the effects of inhaled terbutaline, irrespective of the sequence of $\mathrm{NO}$ and terbutaline administration. Inhaling aerosol generated from $S$-nitroso- $\boldsymbol{N}$-acetylpenicillamine also induced a rapid and profound decrease of $\boldsymbol{R}_{\mathrm{L}}$ from $0.453 \pm 0.022$ to $0.287 \pm 0.022 \mathrm{cmH}_{2} \mathrm{O} / \mathrm{ml} \cdot \mathrm{s}$, which lasted for over $15 \mathrm{~min}$ in guinea pigs bronchoconstricted with methacholine. Our results indicate that low levels of inhaled gaseous NO, or an aerosolized NO-releasing compound are potent bronchodilators in guinea pigs. (J. Clin. Invest. 1992. 90:421-428.) Key words: bronchoconstriction $\bullet$ methacholine $\bullet$ pulmonary resistance $\bullet$ pulmonary compliance
\end{abstract}

\section{Introduction}

Small amounts of inhaled nitric oxide (NO), by diffusing directly from the alveoli into vascular smooth muscle of awake lambs, induce selective pulmonary vasodilation and reverse hypoxic pulmonary vasoconstriction and the heparin-protamine reaction $(1,2)$. A dose-dependent selective pulmonary vasodilator effect of inhaled NO in lambs was observed during a steady-state infusion of U46619, an endoperoxide analogue of thromboxane; tolerance did not occur when lambs inhaled $80 \mathrm{ppm}$ NO for $1 \mathrm{~h}$. Rapid combination of NO with hemoglobin in red blood cells ( 3 ) inactivates the inhaled NO, restricting

Address reprint requests to Dr. W. Zapol, Department of Anaesthesia, Massachusetts General Hospital, Boston, MA 02114.

Received for publication 20 November 1991 and in revised form 10 February 1992.

J. Clin. Invest.

(C) The American Society for Clinical Investigation, Inc. $0021-9738 / 92 / 08 / 0421 / 08 \quad \$ 2.00$

Volume 90, August 1992, 421-428 vasodilation to vessels in the lungs and preventing systemic vasodilation.

NO activates soluble guanylate cyclase, elevates tissue cyclic GMP levels (4), and causes a rapid and pronounced relaxation of precontracted strips of bovine coronary artery (5). Common nitrovasodilators such as sodium nitroprusside and nitroglycerin act by releasing NO (6), and induce relaxation in a variety of vascular and nonvascular smooth muscle cells (7, $8)$. NO and nitrovasodilators induce relaxation by reducing cytoplasmic $\mathrm{Ca}^{2+}$ concentration (9).

NO is the major oxide of nitrogen formed during a variety of high temperature combustion processes and is a common air pollutant. Despite the widely held misconception, NO in low concentrations in air is only slowly oxidized, and so can be studied independently of the effects of its more toxic product, nitrogen dioxide $\left(\mathrm{NO}_{2}\right)(10)$. NO is produced in the hot reducing atmosphere near the glowing cone of a cigarette and is inhaled in smoke in concentrations of 400-1,000 ppm (11). Exposure of lung tissue and guanylate cyclase preparations from lung tissue to cigarette smoke induces a prompt increase in guanylate cyclase activity and cyclic GMP (12). Both in vitro and in vivo studies suggest nitrovasodilators are bronchial smooth muscle relaxants $(13,14)$.

We hypothesized that inhaled NO molecules, which are extremely lipophilic $(15,16)$, would diffuse through the bronchial epithelial barrier to reach airway smooth muscle and produce airway relaxation. We believed that a gas inhalation strategy could overcome many of the problems due to intravenous and aerosol administration of bronchodilators (17). To test this hypothesis, we examined the effects of inhalation of 5-300 ppm NO on airway mechanics in the normal and methacholine bronchoconstricted guinea pig. We also studied the bronchodilator effects of $\mathrm{NO}$ and the $\beta_{2}$ agonist terbutaline, both independently and in concert. We also explored the effects of aerosolizing an NO-releasing compound, $S$-nitroso- $N$-acetylpenicillamine (SNAP) ${ }^{1}$ on airway mechanics in the bronchoconstricted guinea pig. Our data demonstrate that NO is a potent bronchodilator; the concentrations reached to achieve this relaxation are considered safe for human administration (18).

\section{Methods}

\section{Animal preparation}

Male Hartley strain guinea pigs ( $300-440 \mathrm{~g}$ body wt ) were anesthetized with $\alpha$-chloralose $(50 \mathrm{mg} / \mathrm{kg}$ ) and urethane $(500 \mathrm{mg} / \mathrm{kg}$ ) injected intraperitoneally (19). When appropriate anesthesia had been achieved, a tracheal cannula ( $1.65 \mathrm{~mm}$ i.d.) was inserted into the lumen of the cervical trachea through a tracheostomy and tied in place. The guinea pigs were mechanically ventilated in the supine position by a constant-

1. Abbreviations used in this paper: Cdyn, dynamic compliance; met$\mathrm{Hb}$, methemoglobin; $R_{\mathrm{L}}$, pulmonary resistance; SNAP, $S$-nitroso- $N$ acetylpenicillamine. 
volume ventilator (Harvard Apparatus Co., Inc., S. Natick, MA) at 8 $\mathrm{ml} / \mathrm{kg}$ tidal volume and a frequency of 60 breaths/min. One jugular vein was cannulated for the intravenous administration of drugs. After a positive end expiratory pressure of 3-4 $\mathrm{cmH}_{2} \mathrm{O}$ was provided the chest was opened by bilateral excision of the anterior portion of the 6th through 10th ribs so the lungs were exposed to atmospheric pressure (20).

\section{Measurement of lung mechanics}

Guinea pigs were placed in a constant mass body plethysmograph connected to a 10-liter reservoir containing loosely packed copper mesh to maintain a constant temperature (21). Plethysmograph pressure relative to a similar sized reservoir was measured with a differential pressure transducer (Celesco, Canoga Park, CA). Transpulmonary pressure was measured with a differential pressure transducer as the difference between the pressure from a side tap in the tracheal cannula and the pressure inside the plethysmograph. Flow was obtained by electrical differentiation of the volume ( plethysmograph pressure) signal. Volume, flow, and transpulmonary pressure signals were recorded on a strip chart (General Scanning, Watertown, MA). Pulmonary resistance $\left(R_{\mathrm{L}}\right)$ and dynamic compliance ( $C$ dyn $)$ were calculated by a computer program according to the method of von Neergard and Wirz (22, 23 ). The values of $R_{\mathrm{L}}$ and $C$ dyn are the mean of the measurements obtained over $30 \mathrm{~s}$, i.e., 30 tidal volumes.

The inspired gas was a mixture of nitrogen and oxygen blended via a $\mathrm{Y}$ piece, which was then mixed with an NO- and $\mathrm{N}_{2}$-containing gas mixture to produce the correct inspired NO concentration in a 5-liter gas mixing bag. Using volumetrically calibrated flowmeters, varying quantities of $\mathrm{NO}$ mixed with $\mathrm{N}_{2}$ were substituted for pure $\mathrm{N}_{2}$ to obtain the desired NO concentration at an inspired oxygen concentration $\left(\mathrm{FIO}_{2}\right)$ of $0.30-0.32$ (oxygen monitor, Hudson Ventronics Division, Bedford, MA). NO was obtained from Airco Inc. (Murray Hill, NJ) as a mixture containing $1,034 \mathrm{ppm} \mathrm{NO}$ in nitrogen. The gas mixture was then passed through a $3 \mathrm{~cm}$ i.d., 20 -cm-long tube filled with soda lime to scavenge nitrogen dioxide ( 24$)$, and filtered ( $10 \mu \mathrm{m}$ pore size ) before entering the ventilator. A vacuum was applied and adjusted to maintain the gas mixing bag nearly empty continuously providing a fresh gas mixture to the ventilator. Expiratory gas from the ventilator was scavenged using suction. The total inflow gas rate was maintained at 2.5 liter/min. A chemiluminescence $\mathrm{NO} / \mathrm{NO}_{\mathrm{x}}$ analysis (model $14 \mathrm{~A}$, Thermo Environmental Instruments Inc., Franklin, MA) (25) was performed before and after the soda lime-filled tube, and just before the inspiratory valve of the ventilator to assess $\mathrm{NO}$ and $\mathrm{NO}_{2}$ concentrations ( Table I). Over $80 \%$ of source gas $\mathrm{NO}_{2}$ was scavenged in the soda lime filter. At the highest level of NO inhalation (300 ppm), $<4 \mathrm{ppm}$ $\mathrm{NO}_{2}$ was measured in the inspired circuit of the ventilator.

Table I. Chemiluminescence Measurements

\begin{tabular}{lccc}
\hline & \multicolumn{3}{c}{ Analysis } \\
\cline { 2 - 4 } & 1 & \multicolumn{1}{c}{2} & \multicolumn{1}{c}{3} \\
\hline & & $p p m$ & \\
$\mathrm{NO}$ & 26 & 25 & 25 \\
$\mathrm{NO}$ & $<0.5$ & $<0.05$ & $<0.05$ \\
$\mathrm{NO}$ & 115 & 100 & 100 \\
$\mathrm{NO}$ & $<2$ & $<0.1$ & $<0.5$ \\
$\mathrm{NO}$ & 395 & 300 & 300 \\
$\mathrm{NO}_{2}$ & 22 & $<2$ & $<4$ \\
\hline
\end{tabular}

Ventilatory circuit gas analyses: (1) before, (2) after the soda lime filled tube, and (3) just before the inspiratory valve. Values are expressed in vol/vol ppm $\left(1 \mathrm{ml} \mathrm{No} / 10^{6} \mathrm{ml}\right.$ total gas; at $P_{B}=760$ $\mathrm{mmHg}, 1 \mathrm{ppm}$ NO represents $1.34 \mu \mathrm{g} \mathrm{NO} / \mathrm{liter}$ ) and represent the measurements at three differing levels of $\mathrm{NO}$ administration.

\section{Protocol}

19 guinea pigs were studied. Two series of studies were completed on two separate groups of animals according to the following sequence of experiments.

\section{GROUP 1}

Nine guinea pigs were included in three consecutive studies.

Study la: effect of NO on normal bronchial tone. After baseline measurements of $R_{\mathrm{L}}$ and $C$ dyn, we examined the effects on baseline bronchial tone of inhaling $300 \mathrm{ppm}$ NO for $6 \mathrm{~min}$.

Study $1 b$ : dose-response study of intermittent NO inhalation during methacholine infusion. After obtaining baseline measurements of pulmonary resistance and compliance, guinea pigs were given an intravenous infusion of methacholine sufficient to achieve a moderate level of bronchoconstriction (about three to four times the baseline lung resistance). Interanimal variability in responsiveness to methacholine required that we infuse a range of doses $(3.5-12 \mu \mathrm{g} / \mathrm{kg} \cdot \mathrm{min})$ to achieve this level. After at least 2 min of stable $R_{\mathrm{L}}$ (variation $<10 \%$ ), each animal was ventilated with a gas mixture containing $5 \mathrm{ppm}$ NO for 10 min at a constant $\mathrm{FIO}_{2}(0.30-0.32) . R_{\mathrm{L}}$ and $C$ dyn were continuously measured during the $10 \mathrm{~min}$ of $\mathrm{NO}$ exposure, and for $10 \mathrm{~min}$ after ceasing NO inhalation. After these measurements were obtained, the lungs were manually inflated with three times the normal tidal volume to minimize the effects of airway closure, and a stable baseline was reestablished. The entire procedure was then repeated at increasing levels of $10,25,50,100$, and $300 \mathrm{ppm}$ NO. A second exposure to 10 , and then $50 \mathrm{ppm}$ NO for $10 \mathrm{~min}$ was performed, so each guinea pig could be examined for the development of acute tolerance to the effects of NO. After the last exposure to NO, the methacholine infusion was stopped. When $R_{\mathrm{L}}$ and $C$ dyn had stabilized, measurements were again obtained, providing the reference baseline point for the entire study, and $1 \mathrm{~min}$ after lung inflation with three times the normal tidal volume.

Study 1c: Study of tolerance to $1 \mathrm{~h}$ of NO inhalation during methacholine infusion. Guinea pigs were given an infusion of methacholine at a dose sufficient to increase $R_{\mathrm{L}}$ by three- to fourfold. When a stable $R_{\mathrm{L}}$ level had been achieved, the animals were ventilated for $1 \mathrm{~h}$ with a 100 ppm NO containing gas mixture at $\mathrm{FIO}_{2} \mathbf{0 . 3 0 - 0 . 3 2}$. Methacholine infusion was discontinued $10 \mathrm{~min}$ after ceasing NO inhalation. Measurements of $R_{\mathrm{L}}$ and $C$ dyn were obtained every $10 \mathrm{~min}$ over this period, and after methacholine infusion was discontinued before and after lung inflation with three times the tidal volume. Circulating blood methemoglobin (met-Hb) levels were measured spectrophotometrically (26) in each guinea pig with $1 \mathrm{ml}$ of venous blood drawn in $0.01 \mathrm{ml} 15 \%$ liquid EDTA before beginning NO ventilation and after the conclusion of the tolerance study.

\section{GROUP 2}

10 guinea pigs were included in three consecutive studies.

Study 2a: study of the respiratory effects of 80 min of methacholine infusion alone. To evaluate the stability of our animal model of airway constriction, guinea pigs were given an infusion of methacholine sufficient to achieve the same level of bronchoconstriction as in study $1 c$. Animals were ventilated with an oxygen/nitrogen gas mixture at constant $\mathrm{FIO}_{2}(0.30-0.32)$. Methacholine infusion was discontinued after $70 \mathrm{~min}$. Repeated measurements of $R_{\mathrm{L}}$ and $C$ dyn were obtained every 10 min over this period, and after methacholine infusion was discontinued before and after lung inflation with three times the tidal volume.

Study 2b: study of combined bronchodilation by NO and terbutaline aerosol. After baseline measurements, guinea pigs were given a methacholine infusion sufficient to raise their lung resistance to three to four times baseline $R_{\mathrm{L}}$. Then, five guinea pigs were exposed to an aerosol generated from a solution of terbutaline, this was followed $10 \mathrm{~min}$ later by inhaling $100 \mathrm{ppm} \mathrm{NO}$ for $6 \mathrm{~min}$ at a constant $\mathrm{FIO}_{2}(0.30-0.32)$. Terbutaline aerosols, with a mean particle size of $1-2 \mu \mathrm{m}$ and an aerodynamic mass median diameter of $1.0 \mu \mathrm{m}$ were generated by a jet-nebulizer (AeroTech II, CIS-US Inc., Bedford, MA); $4 \mathrm{ml}$ of a $40 \mu \mathrm{g} / \mathrm{ml}$ terbutaline solution were placed in the reservoir of the nebulizer which 
was powered by $4.5 \mathrm{liter} / \mathrm{min}$ air flow. The nebulizer was connected to the $Y$ piece of the ventilator circuit via a stopcock. The other end of the nebulizer was connected to a tube immersed in 3-4 cm water to bypass the gas overflow and maintain the same level of end-expiratory pressure during the nebulization procedure. To deliver the aerosol, the ventilator was disconnected so that the nebulizer circuit was connected to the airway, and 10 breaths of the usual tidal volume were given by alternately clamping the expiratory tube. Five other guinea pigs received a terbutaline aerosol according to the same procedure $6 \mathrm{~min}$ after continuously inhaling $100 \mathrm{ppm}$ NO for $16 \mathrm{~min}$. After the study the methacholine infusion was discontinued until stable $R_{\mathrm{L}}$ values were obtained and then the lungs were inflated with three times the tidal volume to provide final baseline values. Repeated measurements of pulmonary mechanics were obtained every $2 \mathrm{~min}$ during the NO breathing and terbutaline periods.

Study 2c: effects of SNAP nebulization. After at least a 5-min stable period of baseline pulmonary mechanics and $30-45$ min after the completion of study $2 b$, the five guinea pigs that had first received a terbutaline aerosol and then NO inhalation were given a methacholine infusion to raise $R_{\mathrm{L}}$ to three to four times baseline. As a reference value for NO bronchodilator activity, $R_{\mathrm{L}}$ was measured each minute for $10 \mathrm{~min}$ during $100 \mathrm{ppm}$ NO ventilation; NO gas inflow was then ceased. After waiting $10 \mathrm{~min}$ for $R_{\mathrm{L}}$ to return to the bronchoconstricted baseline, 3 $\mathrm{ml}$ of a $200 \mathrm{mM}$ solution of SNAP were placed in the reservoir of the nebulizer and vaporised by $4.5 \mathrm{liter} / \mathrm{min}$ airflow. The nebulizer was connected to the $Y$ piece of the ventilator as previously described, and 20 breaths of the usual tidal volume were given while maintaining a constant $\mathrm{FIO}_{2}(0.30-0.32)$. Repeated measurements of pulmonary mechanics were obtained each minute. Methacholine infusion was discontinued after $15 \mathrm{~min}$ and the lungs were inflated with three times the tidal volume.

\section{Materials}

Drugs used in this study were methacholine chloride, $\alpha$-chloralose, and urethane (Sigma Chemical Co., St. Louis, MO) and terbutaline sulfate (Ciba-Geigy Ltd., Basel, Switzerland). SNAP was synthesized by reacting $\mathrm{N}$-acetylpenicillamine with excess $\mathrm{NaNO}_{2}$ at acidic $\mathrm{pH}$ (27). Product purity was assessed by melting point and $U V$ absorbance spectroscopy. SNAP forms crystals which are stable at $4^{\circ} \mathrm{C}$ for at least $6 \mathrm{mo}(6)$. Fresh $200 \mathrm{mM}$ SNAP solution was prepared in $\mathrm{O}_{2}$-free (gassed with argon) water/ethanol $(1: 1, \mathrm{vol} / \mathrm{vol}) 0.1 \% \mathrm{HCl}$ and stored on ice in gas-tight vials. This solution was stable for several days as determined by UV absorbance spectroscopy.

\section{Statistical analysis}

All data are expressed as the mean \pm SE. Within each group, paired data were analyzed by $(a)$ analysis of variance comparing the individual time periods with the baseline (time course data), and $(b)$ paired $t$ test for multiple comparisons (dose-response slope). Unpaired data (group 2 , study $2 \mathrm{~b}$ ) were compared at the individual time periods by a Student's unpaired $t$ test (GB-Stat, Dynamic Microsystems Inc., Silver Spring, MD). For each animal, the dose of inhaled NO required to decrease $\boldsymbol{R}_{\mathrm{L}}$ to $50 \%$ of the respective baseline during methacholine infusion $\left(E_{50}\right)$ was obtained by $\log$-linear interpolation. A $P$ value $<0.05$ was considered to indicate statistical significance.

\section{Results}

\section{Group 1}

Study 1a: effect of NO on normal bronchial tone. Ventilation with $300 \mathrm{ppm}$ NO for $6 \mathrm{~min}$ rapidly decreased $R_{\mathrm{L}}$ from $0.138 \pm 0.004$ to $0.125 \pm 0.002 \mathrm{cmH}_{2} \mathrm{O} / \mathrm{ml} \cdot \mathrm{s}(P<0.05)$, while $C$ dyn remained unchanged (from $0.600 \pm 0.043$ to $0.608 \pm 0.048 \mathrm{ml} / \mathrm{cmH}_{2} \mathrm{O}$ ) (Fig. 1). $R_{\mathrm{L}}$ returned to control levels $\left(0.134 \pm 0.004 \mathrm{~cm} \mathrm{H}_{2} \mathrm{O} / \mathrm{ml} \cdot \mathrm{s}\right)$ by 4 min after ceasing $\mathrm{NO}$ inhalation.

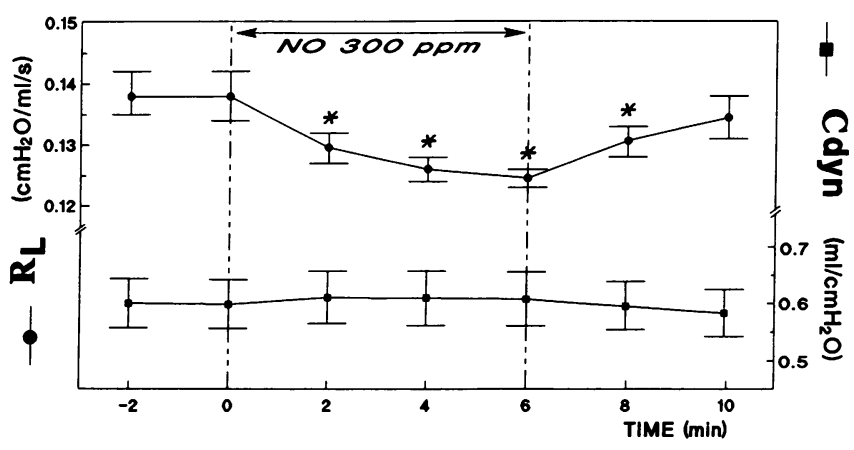

Figure 1. Effects of inhaling $300 \mathrm{ppm}$ NO for $6 \mathrm{~min}$ on the baseline pulmonary resistance $\left(R_{\mathrm{L}}\right)$ and dynamic compliance ( $C$ dyn $)$ of anesthetized guinea pigs $(n=8$, mean $\pm \mathrm{SE}) .{ }^{*} P<0.05$ differs from time 0 .

Study $1 b$ : dose-response study of intermittent NO inhalation during methacholine infusion. An intravenous infusion of methacholine of $8.1 \pm 4.3 \mu \mathrm{g} / \mathrm{kg} \cdot \min$ was used to raise $R_{\mathrm{L}}$ from $0.143 \pm 0.008$ to $0.474 \pm 0.041 \mathrm{cmH}_{2} \mathrm{O} / \mathrm{ml} \cdot \mathrm{s}(P<0.05)$. Ventilation with NO-containing gas mixtures caused a dose-dependent reversal of the bronchoconstriction induced by methacholine infusion (Fig. $2 B$ ). The onset of bronchodilation was rapid, beginning within $30 \mathrm{~s}$ after inhalation (Fig. 3 ). NO inhalation produced significant bronchodilation even at very low inhaled concentrations $(5 \mathrm{ppm})$ where $R_{\mathrm{L}}$ decreased from $0.474 \pm 0.041$ to $0.369 \pm 0.017 \mathrm{cmH}_{2} \mathrm{O} / \mathrm{ml} \cdot \mathrm{s}(P<0.05)$ by 6
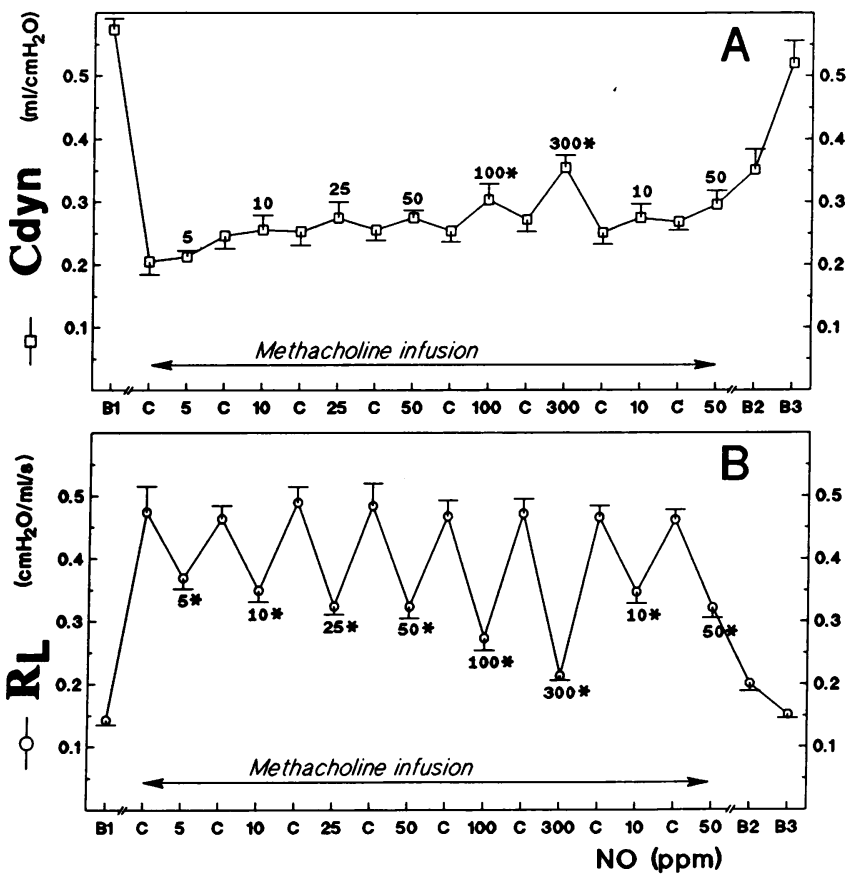

Figure 2. $(A)$ Dynamic compliance and $(B)$ pulmonary resistance during a continuous infusion of methacholine interspaced with inhalation of varying concentrations of $\mathrm{NO}(5-300 \mathrm{ppm})$ at $\mathrm{FIO}_{2} 0.30$ 0.32. " $C$ " indicates the mean value of $R_{\mathrm{L}}$ and $C$ dyn during the control period before each level of NO inhalation. "B" indicates baseline $R_{\mathrm{L}}$ and $C$ dyn before $(B 1)$ and after $(B 2)$ methacholine infusion, and after lung inflation with three times the tidal volume $(B 3)(n=8$, mean $\pm \mathrm{SE}) .{ }^{*} P<0.05$ differs from " $\mathrm{C}$ " value at that level of NO inhalation. 


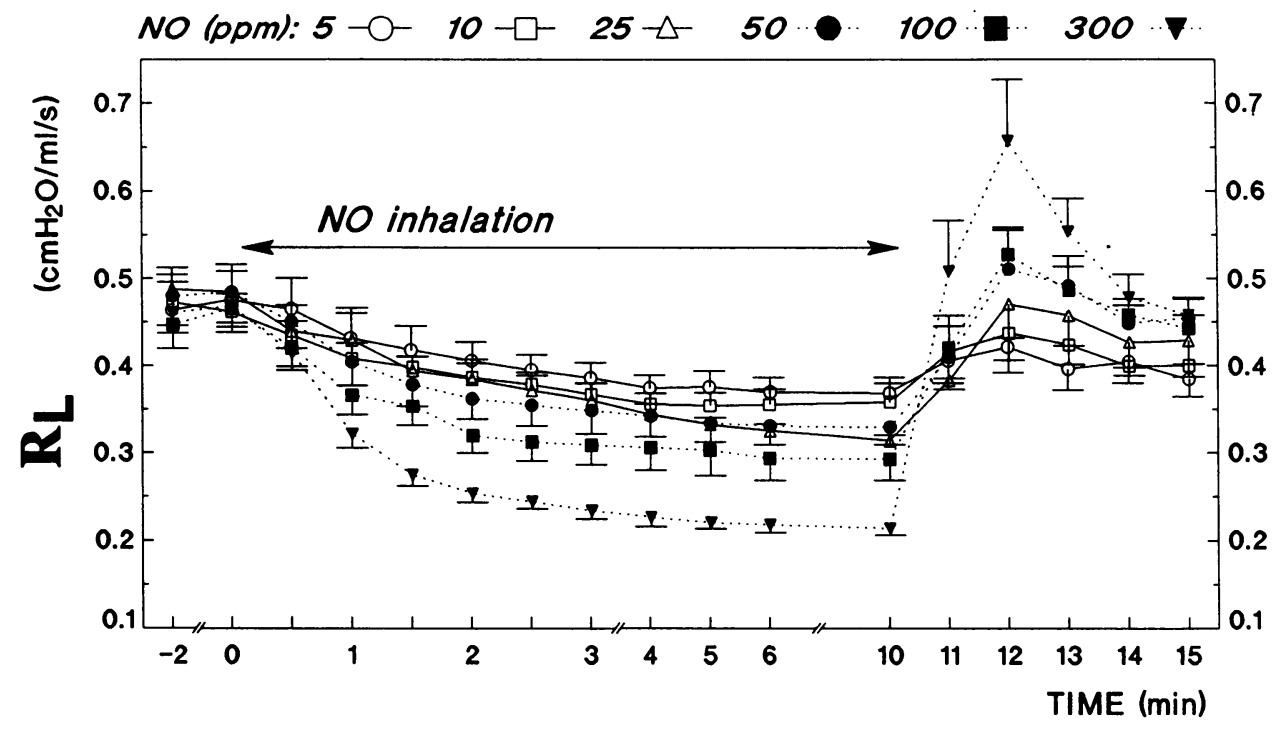

Figure 3. Time course of changes in pulmonary resistance after ventilation with various concentrations of NO (5-300 ppm) and after ceasing $\mathrm{NO}$ gas inflow during a continuous infusion of methacholine $(n=8$, mean \pm SE). min, although a greater and more rapid reduction of airway resistance was obtained at 100 and 300 ppm NO (Fig. 3). Complete reversal of methacholine bronchoconstriction occurred at $300 \mathrm{ppm}$ NO. For each animal a log-linear relationship of $R_{\mathrm{L}}$ dose-response curve values was found ( $r>0.965, P$ $<0.001$ ), and the $\mathrm{EC}_{50}$ was $15.0 \pm 2.1 \mathrm{ppm}$. C dyn significantly increased at the highest $\mathrm{NO}$ doses, from $0.254 \pm 0.017$ to $0.305 \pm 0.025 \mathrm{ml} / \mathrm{cmH}_{2} \mathrm{O}$ at $100 \mathrm{ppm}(P<0.05)$; complete reversal of $C$ dyn occurred at $300 \mathrm{ppm}$ (Fig. $2 A$ ). The offset of bronchodilation was also rapid, $R_{\mathrm{L}}$ returning to baseline at all levels of NO ventilation after 2-3 min (Fig. 3). When NO was removed from the inspired gas after $10 \mathrm{~min}$ inhalation at the highest dose ( $300 \mathrm{ppm}), R_{\mathrm{L}}$ rapidly and transiently increased to $0.654 \pm 0.071 \mathrm{cmH}_{2} \mathrm{O} / \mathrm{ml} \cdot \mathrm{s}$; this level of bronchoconstriction was significantly greater than the $R_{\mathrm{L}}$ value before NO inhalation, $0.469 \pm 0.024 \mathrm{cmH}_{2} \mathrm{O} / \mathrm{ml} \cdot \mathrm{s}(P<0.05)$; however, $R_{\mathrm{L}}$ returned to the control level by $5 \mathrm{~min}$ after ceasing $\mathrm{NO}$ inhalation $\left(0.461 \pm 0.021 \mathrm{cmH}_{2} \mathrm{O} / \mathrm{ml} \cdot \mathrm{s}\right)$ (Fig. 3). The bronchodilator re- sponse to NO reexposure at 10 and $50 \mathrm{ppm}$ did not exhibit any significant difference when compared to the first series of NO exposures (Fig. 2).

Study lc: study of tolerance after $1 \mathrm{~h}$ of $100 \mathrm{ppm}$ NO inhalation during methacholine infusion. An intravenous infusion of methacholine of $7.4 \pm 4.0 \mu \mathrm{g} / \mathrm{kg} \cdot \min$ was used to raise $R_{\mathrm{L}}$ from $0.155 \pm 0.004$ to $0.441 \pm 0.019 \mathrm{cmH}_{2} \mathrm{O} / \mathrm{ml} \cdot \mathrm{s}(P<0.05)$. There was no tolerance to bronchodilation produced by NO inhalation, in that inhaling $100 \mathrm{ppm}$ NO during a steady-state methacholine infusion effectively and stably reduced $R_{\mathrm{L}}$ for $1 \mathrm{~h}$ (Fig. 4). $R_{\mathrm{L}}$ promptly increased to pre-NO exposure levels within a few minutes after ceasing NO inhalation. At the end of the study, after ceasing methacholine infusion and inflating the lungs with three times the tidal volume, the baseline values of $R_{\mathrm{L}}$ did not differ from the level before this study. Methemoglobin levels after the study ranged from $0.5 \%$ to $1.3 \%$ $(0.99 \pm 0.09 \%)$ and were significantly increased above the control values $(0.55 \pm 0.08 \% ; n=8, P<0.05)$.

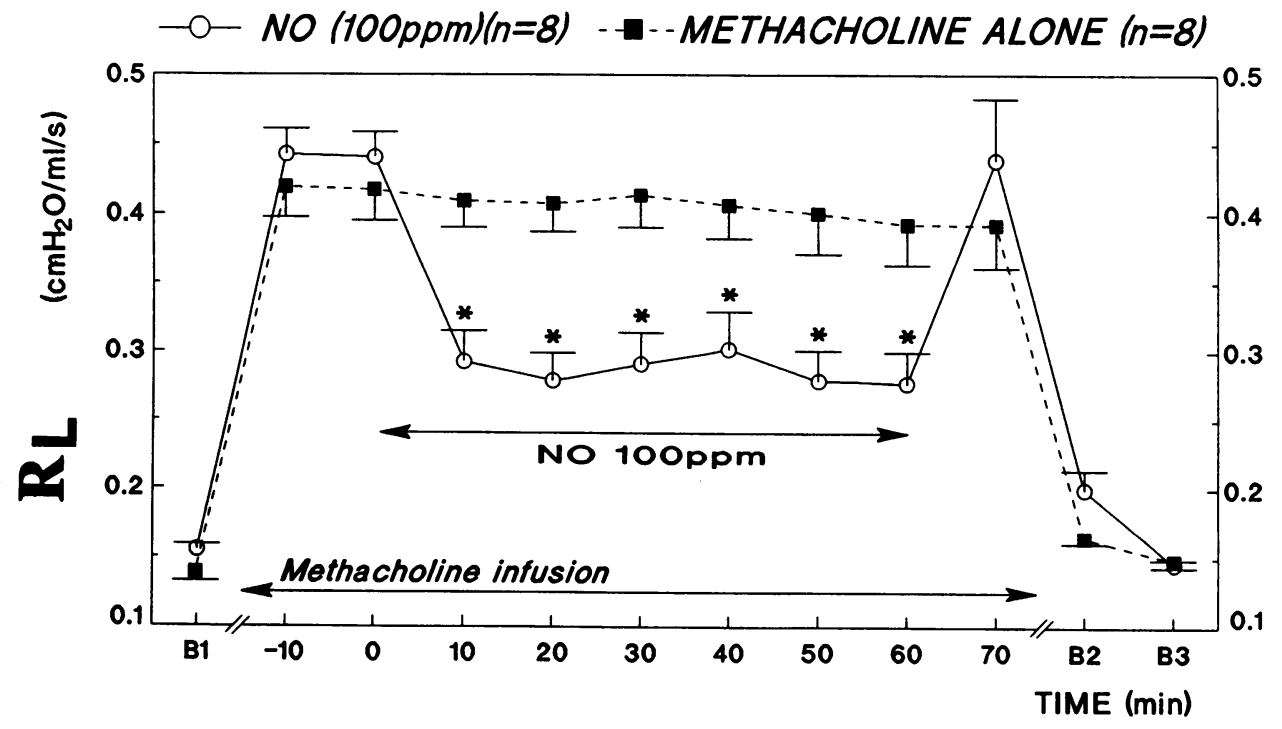

Figure 4. Effects of $80 \mathrm{~min}$ of methacholine infusion alone, and effects of $60 \mathrm{~min}$ of $100 \mathrm{ppm}$ NO inhalation on $R_{\mathrm{L}}$ during a continuous infusion of methacholine. " $B$ " indicates baseline $R_{\mathrm{L}}$ before $(B 1)$ and after (B2) methacholine infusion, and after lung inflation with three times the tidal volume $(B 3)(n$ $=8$ in each group, mean $\pm \mathrm{SE}) .{ }^{*} P$ $<0.05$ value differs from time 0 . 

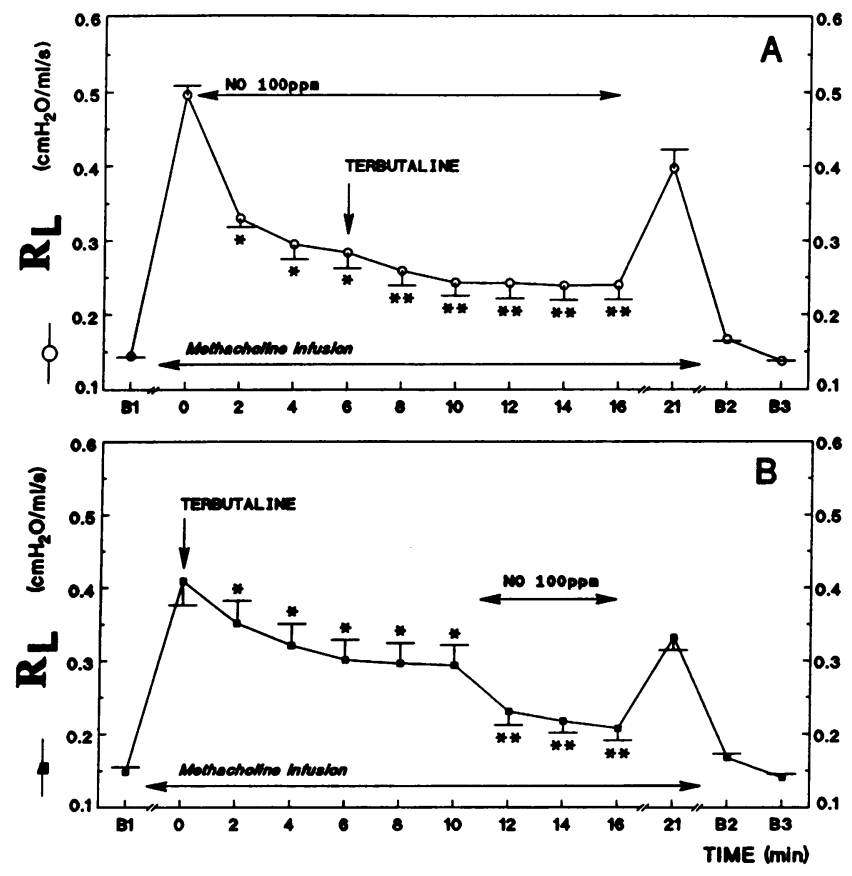

Figure 5. Effects on pulmonary resistance during a continuous infusion of methacholine, of $(A)$ adding terbutaline inhalation $6 \mathrm{~min}$ after continuously breathing $100 \mathrm{ppm}$ nitric oxide (NO) and $(B)$ adding $100 \mathrm{ppm}$ NO inhalation $10 \mathrm{~min}$ after a terbutaline aerosol. " $B$ " indicates baseline $R_{\mathrm{L}}$ before ( $\left.B 1\right)$ and after $(B 2)$ methacholine infusion, and after lung inflation with three times the tidal volume $(B 3)$ ( $n$ $=5$ in each group, mean $\pm \mathrm{SE}) .{ }^{*} P<0.05$ value differs from time 0 , ${ }^{* *} P<0.05$ value differs from value at $(A)$ time $6 \mathrm{~min}$ or $(B)$ at $10 \mathrm{~min}$.

\section{Group 2}

Study 2a: effects of 80 min of methacholine infusion alone. An intravenous infusion of methacholine of $7.1 \pm 3.8 \mu \mathrm{g} / \mathrm{kg} \cdot \mathrm{min}$ was used to raise $R_{\mathrm{L}}$ from $0.139 \pm 0.006$ to $0.416 \pm 0.022$ $\mathrm{cmH}_{2} \mathrm{O} / \mathrm{ml} \cdot \mathrm{s}(P<0.05)$. Our model of producing airway constriction by continuous intravenous methacholine infusion produced stably increased levels of airway resistance for up to 1 $\mathrm{h}$ (Fig. 4), establishing the reliability and reproducibility of the bronchoconstriction baseline for the studies of the efficacy of NO as a bronchodilator.

Study 2b: study of combined bronchodilation by NO and terbutaline aerosol. During a methacholine infusion, breathing $100 \mathrm{ppm}$ NO or administering a terbutaline aerosol in two separate groups of five guinea pigs induced a sustained reduction of $R_{\mathrm{L}}$ (Fig. 5). Adding either terbutaline aerosol or NO inhalation to the other treatment resulted in an overall increase of $69.9 \pm 5.8 \%$ and $69.3 \pm 4.0 \%$ of the maximal bronchodilation respectively, values that did not significantly differ.

Study 2c: effects of SNAP aerosol. In all five guinea pigs, breathing 20 breaths of a SNAP aerosol produced a rapid reduction of the bronchoconstriction induced by a methacholine infusion; $R_{\mathrm{L}}$ decreased from $0.453 \pm 0.022$ to $0.287 \pm 0.022$ $\mathrm{cmH}_{2} \mathrm{O} / \mathrm{ml} \cdot \mathrm{s}$ at $10 \min (P<0.05)$. Maximum bronchodilation lasted about $15 \mathrm{~min}$ and the degree of bronchodilation was comparable to that obtained when the animals inhaled 100 ppm NO before this SNAP aerosol study (Fig. 6). Cdyn increased from $0.299 \pm 0.020$ to $0.365 \pm 0.030 \mathrm{ml} / \mathrm{cmH}_{2} \mathrm{O}(P$ $<0.05$ ), but remained significantly lower than the reference value without methacholine $\left(0.451 \pm 0.025 \mathrm{ml} / \mathrm{cmH}_{2} \mathrm{O}\right)$. The methacholine infusion rate during this study and study $2 \mathrm{~b}$ did not differ $(8.1 \pm 4.3$ and $8.6 \pm 4.7 \mu \mathrm{g} / \mathrm{kg} \cdot \mathrm{min}$, respectively $)$.

\section{Discussion}

This study demonstrates that inhalation of low concentrations of NO rapidly reverses methacholine-induced bronchoconstriction in anesthetized and mechanically ventilated guinea pigs. Bronchodilation continued for at least $1 \mathrm{~h}$ without evidence of tolerance. Bronchoconstriction recurred within minutes of ceasing NO inhalation. Furthermore, the bronchodilator effect of NO was additive with that of terbutaline and independent of the sequence of administration. Inhaling SNAP, an NO donor molecule, induced prompt and long lasting bronchodilation. Bronchoconstriction caused by continuous intravenous methacholine infusion produced a stably elevated level of airway resistance for $1 \mathrm{~h}$.

It is unlikely that the bronchodilation observed in response to NO inhalation is the result of sympathetic reflexes arising from systemic effects of the gas. Whereas inhaled NO reverses

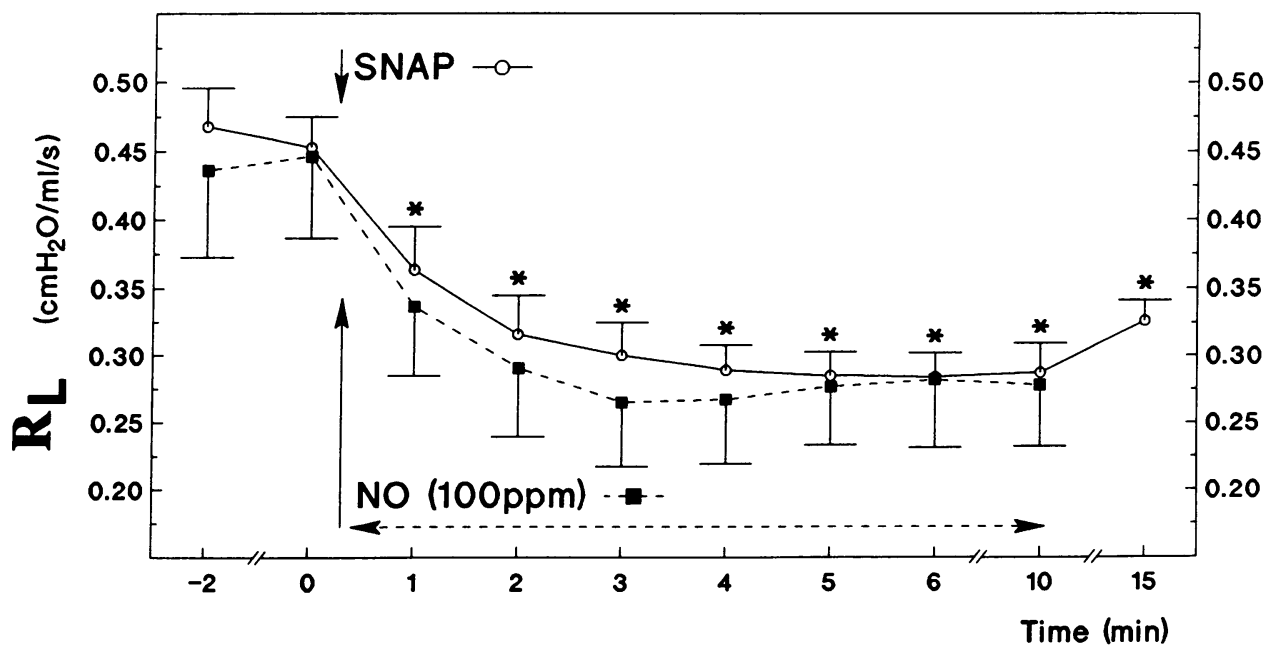

Figure 6. Effects of inhaling NO ( $100 \mathrm{ppm}$ ) for $10 \mathrm{~min}$ or breathing aerosolized SNAP for 20 consecutive breaths on $R_{\mathrm{L}}$ during a continuous methacholine infusion $(n=5$, mean \pm SE). ${ }^{*} P<0.05$ value differs from time 0 . 
pulmonary vasoconstriction resulting from a thromboxane analogue infusion, it had no effect on the systemic blood pressure or vascular resistance in that $\mathrm{NO}$ is inactivated rapidly by binding to hemoglobin (1). It is also unlikely that the decrease in $R_{\mathrm{L}}$ observed after inhaling NO was due to an increase in lung volume inasmuch as there was no change in functional residual capacity as monitored by the plethysmograph volume signal (data not shown). Furthermore, an increase in lung volume should have resulted in a decreased dynamic lung compliance. In our study, $C$ dyn increased with NO inhalation.

$\mathrm{NO}$ gas at high concentration ( $300 \mathrm{ppm})$ was capable of reducing normal bronchial tone (see Fig. 1). NO inhalation rapidly reversed in a dose-dependent manner the bronchoconstriction induced by methacholine infusion. Breathing low concentrations of NO ( $5 \mathrm{ppm})$ produced a significant decrease of $R_{\mathrm{L}}$, suggesting that inhaled NO readily permeates bronchial walls to relax airway smooth muscle. At low NO doses the selective effect on $R_{\mathrm{L}}$, but not $C$ dyn, is consistent with a predominant action on large airways. At higher NO concentrations (i.e., $100 \mathrm{ppm}$ ) effects on $C$ dyn were also observed (see Figs. 2 and 3 ). In vitro, nitroglycerin and sodium nitroprusside relax variously sized bovine airways contracted with carbachol, but appear less effective in relaxing small airways (13). Intravenous nitroglycerin transiently relaxed the trachea in anesthetized adults (28).

Bronchoconstriction recurred within 2-3 min of ceasing NO inhalation (see Fig. 3). After $10 \mathrm{~min}$ of NO inhalation, turning off $\mathrm{NO}$ gas inflow at the highest level of NO exposure ( $300 \mathrm{ppm}$ ) caused a transient period of increased $R_{\mathrm{L}}$, before returning within $5 \mathrm{~min}$ to the baseline bronchoconstricted level (see Fig. 3). We are uncertain why excessive rebound bronchoconstriction occurs. However, it was not observed after rapidly turning off $300 \mathrm{ppm}$ NO with normal bronchial tone (see Fig. 1). Furthermore, we did not observe this bronchoconstrictor effect when more slowly ceasing NO gas inflow over $3 \mathrm{~min}$ (data not shown) or after ceasing NO ventilation at lower NO concentrations. Therefore, we can only speculate that this represents either a mechanical consequence of a rapid change in $R_{\mathrm{L}}$, or a transient dysregulation of intracellular second messengers involved in contraction-relaxation (e.g., myoplasmic $\mathrm{Ca}^{2+}$ levels).

Small concentrations of inhaled NO (40 ppm) almost totally reversed the pulmonary hypertension induced by infusion of a thromboxane analog in awake lambs (1). Examining similar constrictor agonists, a reduced sensitivity of tracheal as compared to vascular smooth muscle to NO relaxant effects has been clearly shown by in vitro experiments exposing both denuded tissues to NO; furthermore, tracheal smooth muscle showed a smaller increase of cyclic GMP activity (29). The effects of NO on isolated epithelium-intact guinea pig tracheal strips constricted with carbachol has been shown to be significantly less than on epithelium-denuded strips (30). How the epithelial layer reduces the effects of $\mathrm{NO}$ is unclear. Epithelium may provide a diffusion barrier for NO, or could act as a metabolic sink. Another possible contributor is mucus on the surface of the epithelial layer, which is known to bind to oxygen radicals (31).

Guinea pig trachea possesses an inhibitory (bronchodilator) nonadrenergic, noncholinergic innervation associated with cholinergic nerves which may be partly mediated by NO $(32,33)$. Although our data do not allow us to assess if there are airway sources of endogenous NO in vivo, it clearly demonstrates that NO has the capacity to relax contracted airways in vivo.

Organic nitrate esters, such as nitroglycerin, require cysteine to liberate NO. Thiol depletion of smooth muscle by treatment with nitroglycerin results in the development of refractoriness to vasodilation (34). Our data indicate that no tolerance to the bronchodilator effect of breathing $100 \mathrm{ppm}$ NO occurred for $1 \mathrm{~h}$ (see Fig. 4). Tolerance is not expected since NO directly activates intracellular guanylate cyclase to elicit relaxation.

NO combines with hemoglobin forming NO-Hb with an affinity 1,500 times greater than that measured for carbon monoxide (35). NO-Hb is oxidized to met-Hb in the presence of oxygen, and met-Hb is reduced to ferrous hemoglobin by met- $\mathrm{Hb}$ reductase in red blood cells. We measured a minor but significant increase of circulating met-Hb levels from $0.55 \pm 0.08 \%$ to $0.99 \pm 0.09 \%$ when guinea pigs were exposed to $100 \mathrm{ppm}$ NO for $1 \mathrm{~h}$.

Inhaling either a terbutaline aerosol or NO gas induced prompt and sustained bronchodilation in our methacholine challenged guinea pigs, and the subsequent administration of the other agent always produced an additive reduction of $R_{\mathrm{L}}$ independent of the sequence of administration (see Fig. 5). Cyclic AMP and cyclic GMP are believed to be the major intracellular second messenger pathways mediating airway smooth muscle relaxation (36). Analogs of cyclic AMP and cyclic GMP induce a concentration-dependent relaxation of guinea pig tracheal smooth muscle but cyclic GMP appears less effective than cyclic AMP (6). However both nucleotides induce functionally additive relaxation of the trachea, each neither potentiating nor depressing the effects of the other (37). Our results indicate that in vivo activation of either cyclic nucleotide pathway by NO and terbutaline induces functionally additive bronchodilation.

We also evaluated the effects of inhaling aerosolized SNAP, an NO-releasing compound. Sodium nitroprusside and NO can react with cysteine to form $S$-nitrosocysteine; this nitrosylation can also occur with other endogenous thiols. $S$-nitrosothiols are potent activators of guanylate cyclase and may partly account for the intracellular activation of guanylate cyclase by NO and related NO-containing vasodilators $(6,38)$. SNAP is stable for $4.6 \mathrm{~h}$ when exposed to room air at $37^{\circ} \mathrm{C}$ in a phosphate-buffered $\mathrm{pH} 7$ solution; however in physiological solutions SNAP rapidly decomposes to release NO (6). Our results indicate that inhaling a SNAP aerosol produced a prompt and profound decrease of $R_{\mathrm{L}}$ in the methacholine constricted guinea pig which lasted over $15 \mathrm{~min}$ (see Fig. 6). Large, inhaled doses of SNAP aerosol can induce pulmonary and systemic vasodilation in awake spontaneously breathing lambs with an acutely constricted pulmonary circulation due to U46619 infusion (unpublished data); in contrast, systemic vasodilation has not occurred while breathing NO gas. However, in this study we did not evaluate the effects of NO or SNAP inhalation on the systemic circulation. Inhaled nitroprusside bronchodilated methacholine constricted guinea pigs but produced marked systemic hypotension (14). The bronchodilator effect of the SNAP aerosol was similar to that produced by inhaling $100 \mathrm{ppm}$ NO (see Fig. 6). We estimate the total amount of inhaled aerosolized SNAP to be $\sim 350 \mu \mathrm{g}$, of which only a fraction, estimated near $30 \%$, deposits into the lungs, 
i.e., $100 \mu \mathrm{g}$. Administering $100 \mathrm{ppm} \mathrm{NO}$ by inhalation to guinea pigs, we estimate an inhaled uptake of $7 \mu \mathrm{g} \mathrm{NO}$ per min.

If our results are to be extended to clinical inhalation of $\mathrm{NO}$ as a bronchodilator substance, it will require a thorough understanding of its metabolic fate and toxicity. The inhalation toxicology of inhaled $\mathrm{NO}$ and $\mathrm{NO}_{2}$ at high concentration has been difficult to ascertain separately because of the oxidation of $\mathrm{NO}$ to $\mathrm{NO}_{2}$ in the presence of oxygen, the oxidation rate being dependent on the temperature, the initial concentration of $\mathrm{NO}$ and the $\mathrm{FIO}_{2}$. The oxidation rate of $10 \mathrm{ppm} \mathrm{NO}$ in air at $20^{\circ} \mathrm{C}$ is slow and $7 \mathrm{~h}$ is required for $50 \%$ oxidation (10). Inhaled NO diffuses through the lung and binds with hemoglobin in erythrocytes; in contrast, $\mathrm{NO}_{2}$ causes pathological changes in airways and alveoli $(39,40)$. The U.S. Occupational Safety and Health Administration has set the time-weighted average permitted $\mathrm{NO}$ level for breathing $8 \mathrm{~h}$ a day at the workplace at $25 \mathrm{ppm}$ and the $\mathrm{NO}_{2}$ ceiling at $5 \mathrm{ppm}(18)$. An inhaled NO concentration of $15.0 \pm 2.1 \mathrm{ppm}$ was required to reduce $R_{\mathrm{L}}$ by $50 \%$ of the induced bronchoconstriction. Therefore effective bronchodilator concentrations of NO are likely to be safe.

It was recently reported that inhaling $5-80 \mathrm{ppm} \mathrm{NO}$ by patients with adult respiratory distress syndrome (41), and in neonates with persistent pulmonary hypertension of the newborn (42) produced a marked improvement of oxygen exchange and arterial oxygen tension. It is possible that some of this improvement may be due to bronchodilation and not simply vasodilation of ventilated lung regions.

Because NO inhalation induces rapid and potent bronchodilation in methacholine bronchoconstricted guinea pigs we believe NO inhalation represents an alternative approach to treating various causes of bronchoconstriction such as asthma and bronchospasm. Rapid inactivation of inhaled NO by red blood cells will prevent any systemic hemodynamic side effects. Thus an NO gas inhalation strategy should overcome the deleterious side effects of infusing or inhaling NO-releasing compounds. Selective delivery of inhaled NO gas to ventilated lung regions should vasodilate only these regions, preventing the ventilation-perfusion inequalities produced by inhaled bronchodilators in patients with asthma (43). Inhalation of NO gas and NO-releasing compounds may provide a novel and potent therapeutic approach for bronchodilator therapy.

\section{Acknowledgments}

The authors would like to thank Dr. A. Zaslavsky for statistical assistance.

This study was supported by U.S. Public Health Service grants HL42397 and HL-19170. Dr. P. Dupuy was the recipient of Lavoisier and Philippe Foundation grants. Dr. C. Frostell was supported by a Fogarty International Fellowship.

\section{References}

1. Frostell, C., M. D. Fratacci, J. C. Wain, R. M. Jones, and W. M. Zapol. 1991. Inhaled nitric oxide: a selective pulmonary vasodilator reversing hypoxic pulmonary vasoconstriction. Circulation. 83:2038-2047.

2. Fratacci, M. D., C. Frostell, T.-Y. Chen, J. C. Wain, D. R. Robinson, and W. M. Zapol. 1991. Inhaled nitric oxide: a selective pulmonary vasodilator of heparin-protamine vasoconstriction in sheep. Anesthesiology. 75:990-999.

3. Gruetter, C. A., D. Y. Gruetter, J. E. Lyon, P. J. Kadowitz, and L. J. Ignarro. 1981. Relationship between cyclic 3':5'-monophosphate formation and relaxation of coronary arterial smooth muscle by glyceryl trinitrate, nitroprus- side, nitrite and nitric oxide: effects of methylene blue and methemoglobin. $J$. Pharmacol. Exp. Ther. 219:181-186.

4. Arnold, W. P., C. K. Mittal, S. Katsuki, and F. Murad. 1977. Nitric oxide activates guanylate cyclase and increases guanosine $3^{\prime}: 5^{\prime}$-cyclic monophosphate levels in various tissue preparations. Proc. Natl. Acad. Sci. USA. 74:3203-3207.

5. Gruetter, C. A., B. K. Barry, D. B. McNamara, D. Y. Gruetter, P. J. Kadowitz, and L. J. Ignarro. 1979. Relaxation of bovine coronary artery and activation of coronary arterial guanylate cyclase by nitric oxide, nitroprusside and a carcinogenic nitrosamine. J. Cyclic Nucleotide Protein Phosphorylation Res. 5:211-244.

6. Ignarro, L. J., H. L. Lippton, J. C. Edwards, W. H. Baricos, A. L. Hyman, P. J. Kadowitz, and C. A. Gruetter. 1981. Mechanism of vascular smooth muscle relaxation by organic nitrates, nitrites, nitroprusside and nitric oxide: evidence for the involvement of S-nitrosothiols as active intermediates. J. Pharmacol. Exp. Ther. 218:739-749.

7. Katsuki, S., and F. Murad. 1977. Regulation of adenosine cyclic 3',5'monophosphate and guanosine cyclic 3',5'-monophosphate levels and contractility in bovine tracheal smooth muscle. Mol. Pharmacol. 13:330-341.

8. Katsuki, S., W. Arnold, C. Mittal, and F. Murad. 1977. Stimulation of guanylate cyclase by sodium nitroprusside, nitroglycerin and nitric oxide in various tissue preparations and comparison to the effects of sodium azide and hydroxylamine. J. Cyclic Nucleotide Protein Phosphorylation Res. 3:23-35.

9. Morgan, J. P., and K. G. Morgan. 1984. Alteration of cytoplasmic ionized calcium levels in smooth muscle by vasodilators in ferret. J. Physiol. (Lond.). 357:539-551.

10. Austin, A. T. 1967. The chemistry of the higher oxides of nitrogen as related to the manufacture, storage and administration of nitrous oxide. $\mathrm{Br}$. $\mathrm{J}$. Anaesth. 39:345-350.

11. Norman, V., and C. H. Keith. 1965. Nitrogen oxides in tobacco smoke. Nature (Lond.). 205:915-916.

12. Arnold, W. P., R. Aldred, and F. Murad. 1977. Cigarette smoke activates guanylate cyclase and increases guanosine 3',5'-monophosphate in tissues. Science (Wash. DC). 198:934-936.

13. Gruetter, C. A., C. E. Childres, M. K. Bosserman, S. M. Lemke, J. G. Ball, and M. A. Valentovic. 1989. Comparison of relaxation induced by glyceryl trinitrate, isosorbide dinitrate and sodium nitroprusside in bovine airways. Am. Rev. Respir. Dis. 139:1192-1197.

14. Jamieson, D. D., and K. M. Taylor. 1979. Comparison of the bronchodilator and vasodilator activity of sodium azide and sodium nitroprusside in the guinea-pig. Clin. Exp. Pharmacol. Physiol. 6:515-525.

15. Shaw, A. W., and A. J. Vosper. 1977. Solubility of nitric oxide in aqueous and nonaqueous solvents. J. Chem. Soc. Faraday Trans. 1. 73:1239-1244.

16. Young, C. L. 1981. Solubility data. Nitric oxide-organic liquids system. Solubility Data Series. 8:336-351.

17. Rall, T. W. 1990. Drugs used in the treatment of asthma. In The Pharmacological Basis of Therapeutics. A. Goodman Gillman, T. W. Rall, A. S. Nies, and P. Taylor, editors. Pergamon Press, Inc., New York. 618-637.

18. Centers for Disease Control. 1988. Recommendations for Occupational Safety and Health Standard. MMWR. 37 (Suppl. No. S-7):21.

19. Drazen, J. M., C. S. Venugopalan, and M. W. Schneider. 1980. Alteration of histamine response by $\mathrm{H}_{2}$-receptor antagonism in the guinea pig. J. Appl. Physiol. 48:613-618.

20. Shore, S. A., and J. M. Drazen. 1989. Degradative enzymes modulate airway responses to intravenous neurokinins A and B. J. Appl. Physiol. 67:25042511.

21. Amdur, M. O., and J. Mead. 1958. Mechanics of respiration in unasthetized guinea pigs. Am. J. Physiol. 192:364-368.

22. Von Neergard, K., and K. Wirz. 1927. Über eine Methode zur Messung der Lungenelastizitat am lebenden Menschen, insbesondere beim Emphysem. $Z$. Klin. Med. 105:35-50.

23. Von Neergard, K., and K. Wirz. 1927. Die Messung der Stroemungs widerstaende in den Atemwegen des Menschen, insbesondere bei Asthma und Emphysem. Z. Klin. Med. 105:52-82.

24. Oda, H., S. Kusumoto, and T. Nakajima. 1975. Nitrosyl-hemoglobin formation in the blood of animals exposed to nitric oxide. Arch. Environ. Health. 30:453-456.

25. Fontijn, A., A. J. Sabadell, and R. J. Ronco. 1970. Homogeneous chemiluminescent measurement of nitric oxide with ozone. Anal. Chem. 42:575-579.

26. Zwart, A., A. Buursma, B. Oeseburg, and W. G. Zijlstra. 1981. Determination of hemoglobin derivatives with the IL282 CO-oximeter as compared with a manual spectrophotometric five wavelength method. Clin. Chem. 27:1903-1907.

27. Field, L., R. V. Dilts, R. Ramanathan, P. G. Lenhert, and G. E. Carnahan 1978. An unusually stable thionitrite from $\mathrm{N}$-acetylD,L-penicillamine; X-ray crystal and molecular structure of 2-(acetylamino)-2-carboxy-1,1-dimethylethyl thionitrite. J. Chem. Soc. (Chem. Commun.). 249-250.

28. Byrick, R. J., E. G. Hobbs, R. Martineau, and W. H. Noble. 1983. Nitroglycerin relaxes large airways. Anesth. Analg. 62:421-425.

29. Buga, G. M., M. E. Gold, K. S. Wood, G. Chaudhuri, and L. J. Ignarro. 1989. Endothelium-derived nitric oxide relaxes nonvascular smooth muscle. Eur. J. Pharmacol. 161:61-72. 
30. Munakata, M., Y. Masaki, I. Sakuma, H. Ukita, Y. Otsuka, Y. Homma, and Y. Kawakami. 1990. Pharmacological differentiation of epithelium-derived relaxing factor from nitric oxide. J. Appl. Physiol. 69:665-670.

31. Cross, C. E., B. Halliwell, and A. Allen. 1984. Antioxidant protection: a function of tracheobronchial and gastrointestinal mucus. Lancet. $i: 1328-1330$.

32. Chesrown, S. E., C. S. Venugopalan, W. M. Gold, and J. M. Drazen. 1980. In vivo demonstration of nonadrenergic inhibitory innervation of the guinea pig trachea. J. Clin. Invest. 65:314-320.

33. Belvisi, M. G., D. Stretton, and P. J. Barnes. 1991. Nitric oxide as an endogenous modulator of cholinergic neurotransmission in guinea-pig airways. Eur. J. Pharmacol. 198:219-221.

34. Feelisch, M., and E. A. Noack. 1987. Correlation between nitric oxide formation during degradation of organic nitrates and activation of guanylate cyclase. Eur. J. Pharmacol. 139:19-30.

35. Gibson, Q. H., and F. J. W. Roughton. 1957. The kinetics and equilibria of the reactions of nitric oxide with sheep haemoglobin. J. Physiol. (Lond.). 136:507-526.

36. Torphy, T. J., H. L. Zhou, M. Burman, and L. B. F. Huang. 1990. Role of cyclic nucleotide phosphodiesterase isozymes in intact canine trachealis. $\mathrm{Mol}$. Pharmacol. 39:376-384.

37. Heaslip, R. J., F. R. Giesa, T. J. Rimele, and D. Grimes. 1987. Co-regula- tion of tracheal tone by cyclic AMP-and cyclic GMP-dependent mechanisms. $J$. Pharmacol. Exp. Ther. 243:1018-1026.

38. Ignarro, L. J., and C. A. Gruetter. 1980. Requirement of thiols for activation of coronary arterial guanylate cyclase by glyceryl trinitrate and sodium nitrite: possible involvement of S-nitrosothiols. Biochim. Biophys. Acta. 631:221231.

39. Morrow, P. E. 1984. Toxicological data on $\mathrm{NO}_{\mathrm{x}}$ : an overview. J. Toxicol. Environ. Health. 13:205-227.

40. Nakajima, T., H. Oda, S. Kasumoto, and H. Mogami. 1980. Biological effects of nitrogen dioxide and nitric oxide. In Nitrogen Oxides and their Effects on Health. S. D. Lee, editor. Ann Arbor Science, Michigan. 121-141.

41. Falke, K., R. Rossaint, U. Pison, K. Slama, F. Lopez, B. Santak, and W. M. Zapol. 1991. Inhaled nitric oxide selectively reduces pulmonary hypertension in severe ARDS and improves gas exchange as well as right heart ejection fraction: a case report. Am. Rev. Respir. Dis. 143:248a. (Abstr.)

42. Roberts, J. D., D. M. Polaner, I. D. Todres, P. Lang, and W. M. Zapol. 1991. Inhaled nitric oxide: a selective pulmonary vasodilator for the treatment of persistent pulmonary hypertension of the newborn. Circulation. (Suppl. II) 84:1279a. (Abstr.)

43. Wagner, P. D., D. R. Dantzker, V. E. Iacovoni, W. C. Tomlin, and J. B. West. 1978. Ventilation-perfusion inequality in asymptomatic asthma. Am. Rev. Respir. Dis. 118:511-524. 